\title{
Processing of emotional adjectives: Evidence from startle EMG and ERPs
}

\author{
CORNELIA HERBERT, ${ }^{1}$ JOHANNA KISSLER,,${ }^{1}$ MARKUS JUNGHÖFER,,${ }^{1,2}$ PETER PEYK, ${ }^{1}$ \\ AND BRIGITTE ROCKSTROH ${ }^{1}$ \\ ${ }^{1}$ Department of Psychology, University of Konstanz, Konstanz, Germany \\ ${ }^{2}$ Institute for Biomagnetism and Biosignal Analysis, University of Münster, Münster, Germany
}

\begin{abstract}
Affective startle modulation in the electromyographic (EMG) response, auditory startle evoked potentials, and visually evoked potentials (VEPs) were assessed while subjects evaluated pleasant, unpleasant, and neutral adjectives. Acoustic startle probes were presented at random time points 2.5-4.0 s after word onset. The visual P2 and P3 potentials were generally larger during processing of emotional than of neutral adjectives. In contrast, the late positive component was enhanced and was correlated with larger EMG startle responses and auditory startle evoked potential P3 amplitudes for pleasant words only. During internal cognitive activity, the startle reflex represents a measure of "processing interrupt." Thus the startle tone interrupted processing of particularly pleasant adjectives and caused realerting to environmental stimuli. Specific effects for pleasant material may arise from a "positivity offset," favoring responses to pleasant material at lower arousal levels.
\end{abstract}

Descriptors: Startle reflex, P3, LPC, Emotion, Word processing, Valence, Arousal, Event-related brain potential

The eyeblink component of the human startle reflex to a sudden loud noise is sensitive to various manipulations of the context in which the startle eliciting tone is presented. For instance, the startle eyeblink has been found to be amplified when people view unpleasant pictures and reduced when viewing pleasant pictures (for review, see Lang, Bradley, \& Cuthbert, 1990). The impact of emotion on startle reflex modulation has been interpreted as emotional priming (Lang, 1995) in which emotions are viewed as action dispositions that prepare the organism to respond to environmental stimuli, ultimately improving survival by approaching or by avoiding certain stimuli. Thus, reflexes associated with an aversive response set such as the defensive startle reflex are facilitated during processing of unpleasant information and inhibited for pleasant emotion. This pattern of affective startle modulation has often been reported when emotional pictures are viewed (e.g., Cuthbert, Bradley, \& Lang, 1996; Lang et al., 1990; Schupp, Cuthbert, Bradley, Birbaumer, \& Lang, 1997; Vrana, Spence, \& Lang, 1988).

Research was supported by the Heidelberg Academy of Sciences (Mind and Brain Programme) and the Center for Junior Scientists at the University of Konstanz. We thank Scott Vrana, Steve Crites, and two anonymous reviewers for helpful comments on an earlier version of the manuscript. Many thanks are also extended to Irene Winkler and Alexandra Weiss for help with data collection and analysis.

Address reprint requests to: Cornelia Herbert, Department of Psychology, University of Konstanz, Zentrum für Psychiatrie Reichenau (ZPR), Feuersteinstrasse 55, 78479 Reichenau-Lindenbühl, Germany. E-mail: cornelia.herbert@uni-konstanz.de.

Konstanzer Online-Publikations-System (KOPS)
Additional experimental and cognitive factors influence the startle eyeblink response patterns in specific affective contexts: During emotional anticipation (Sabatinelli, Bradley, \& Lang, 2001) or emotional imagery (e.g., Miller, Patrick, \& Levenston, 2002; Robinson \& Vrana, 2000), startle facilitation has been found for pleasant and unpleasant events alike. These findings have been attributed to differences in processing demands (Miller et al., 2002). Whereas picture viewing requires perceptual processing of an external stimulus, text-driven emotional imagery involves internal associative memory processing, in which resources are directed away from perceptual processing and allocated toward internal, memory-based processing. Under such circumstances, the startle reflex is assumed to mobilize the organism to respond to significant changes in the environment by interrupting internally focused processes (Anthony \& Graham, 1985; Miller et al., 2002). This sudden reactivation of the sensory systems is thought to lead to facilitation of the blink reflex. Accordingly, startle blink amplitude has been found to be increased during internal cognitive activity (Panayiotou \& Vrana, 1998) and the magnitude of startle potentiation during internal processing appears to vary with the depth of mental engagement (Miller et al., 2002).

In addition to a startle eyeblink, startling tones also elicit an auditory evoked P3 in the event-related brain potential - the socalled probe P3 (Ford \& Pfefferbaum, 1991; Putnam \& Roth, 1990). Picture viewing studies that have simultaneously investigated affective modulation of the electromyographic (EMG) startle response and the auditory evoked probe P3 (Cuthbert, 
Schupp, Bradley, McManis, \& Lang, 1998; Schupp et al., 1997) have found that the $\mathrm{P} 3$ response to the startle tone is significantly attenuated when subjects are engaged in viewing either pleasantly or aversively arousing pictures. This arousal-driven probe P3 modulation pattern has been interpreted as a consequence of greater attentional engagement by highly arousing emotional pictures compared to low arousing neutral foreground pictures, such that fewer processing resources are left to process the startle tone (Cuthbert et al., 1998; Schupp et al., 1997).

Network models of emotion predict an impact of emotional word content on physiological responses. Linguistic expressions are assumed to be stored within semantic networks that encompass links to all aspects of their linguistic and pragmatic usage and emotional connotations (Bower, 1981; Lang, 1979). Thus, the word gun, for example, not only represents the instrument itself, but includes links to its operations, use, purpose, and consequences as well as their emotional evaluation (Bower, 1981). Lang, Greenwald, Bradley, and Hamm (1993) further assume that not only associated semantic but also physiological and motor response information is coactivated in such associative networks, lending further momentum to the hypothesis that physiological responses such as the startle eyeblink or probe P3 should be modified by emotional language stimuli as foregrounds.

Similarities in the way the human organism deals with pictorial and linguistic emotion stimuli have been reported in that processing of emotional words and pictures alike has been found to be associated with larger brain event-related P3 and late positive components (LPC) responses than the processing of neutral stimuli (Chapman, McCrary, Chapman \& Martin, 1980; Cuthbert, Schupp, Bradley, Birbaumer \& Lang, 2000; Keil et al., 2002; Naumann, Bartussek, Diedrich \& Laufer, 1992). Concerning peripheral physiological responses, processing of emotional words has been shown to induce similar, albeit less pronounced, EMG corrugator and zygomaticus responses as processing of emotional pictures (Larsen, Norris, \& Cacioppo, 2003). Skin conductance is also increased in response to aversive in comparison to neutral words, both during subliminal and supraliminal word presentation (Silvert, Delplanque, Bouwalerh, Verpoort, \& Sequeira, 2004).

Aitken, Siddle, and Lipp (1999) used threat and nonthreat words in a startle paradigm with startle tone onset after $60-\mathrm{ms}$, 120-ms, 240-ms, and 2000-ms lead intervals to investigate physiological responses to fear-relevant material in participants with normal, low, or high anxiety levels. The study yielded larger foreground effects for threat than for nonthreat related words, that is, larger blink facilitation at $60-\mathrm{ms}$ and larger inhibition at 240-ms lead intervals. These effects were somewhat more pronounced in highly anxious subjects. No significant impact of emotional category was found for either the 120-ms or the 2000ms lead interval. In a similar study with highly anxious children, Waters, Lipp, and Cobham (2000) have found a tendency for larger startle eyeblink responses during threatening words at 60ms lead intervals and some evidence of increased inhibition at 240 $\mathrm{ms}$ but no selective influence of emotional category at $3500 \mathrm{~ms}$. These results are noteworthy in relationship to the literature on affective startle modulation with unpleasant emotional pictures as here reliable effects are often found with lead intervals of 2000 $\mathrm{ms}$ and longer, with the largest facilitation occurring at about $3800 \mathrm{~ms}$.

Lipp, Blumenthal, and Adam (2001) further demonstrated effects of attentional engagement on startle responses during letter reading: When subjects directed their attention to visually presented single letters in an active paradigm, responses to a suddenly appearing startling tone were facilitated at $60-\mathrm{ms}$ and 3500-ms lead intervals and inhibited at 240-ms lead intervals. This suggests an impact of task involvement for startle responses at longer lead intervals when perceptually relatively simple language stimuli are used as foregrounds.

More related to the current study, startle modulation and visual ERP responses to body-related, pain-related, and neutral adjectives were investigated by Knost, Flor, Braun, and Birbaumer (1997) in patients with prechronic pain and comparison subjects. The authors found generally enhanced startle eyeblink responses $1.25 \mathrm{~ms}$ after the onset of body- and pain-related adjectives in comparison to neutral adjectives that were presented for $500 \mathrm{~ms}$. In parallel with the startle EMG results, both groups also had larger visually evoked LPC for body- and pain-related words. Auditory evoked potentials in response to the startle tone were not reported.

Together the literature suggests that at least during initial phases of processing, passive viewing of words dealing with personal threat and physical harm modulates the defensive startle eyeblink response. For pleasant words and at longer lead intervals, the question of affective startle modulation with emotional words as foregrounds is largely open. Likewise, central nervous indices of startle tone processing (probe P3) have not been assessed with words as foregrounds, and the relationship between cortical processing of affective foreground stimuli as reflected in the visually evoked event-related potential and startle reflex physiology has, in general, scarcely been addressed.

Here we investigate the relationship of peripheral EMG and central nervous ERP indices of the human startle response at long lead intervals using pleasant, unpleasant, and neutral emotional adjectives in an active evaluation task.

\section{Methods \\ Participants}

Thirty-three healthy student volunteers ( 15 women, 18 men) received course credit or a financial bonus of 10 Euros for participation. Strong smokers (more than 20 cigarettes a day) were excluded from the experiment as heavy smoking influences startle amplitude (Postma, Kumari, Sharma, Hines, \& Gray, 2001). The data of 4 participants had to be discarded because no measurable startle responses could be obtained. Data of another 3 participants had to be rejected from the analysis because of recording errors. The remaining 26 participants (mean age 26 years; 10 women, 16 men) were native speakers of German and right-handed as determined by handedness scores on the Edinburgh Handedness Inventory (Oldfield, 1971). Upon interview, participants reported no drug abuse, neurological, mental, or chronic bodily diseases, or medication for any of these. All volunteers agreed to participate after reading a detailed consent form approved by the University of Konstanz Institutional Review Board.

\section{Stimulus Materials and Design}

In accordance with several other affective word processing studies (e.g., Bernat, Bunce \& Shevrin, 2001; Bradley, Mogg, \& Williams, 1994; Cacioppo, Crites, \& Gardner, 1996; Fossati et al., 2003; Knost et al., 1997), we used emotional adjectives as stimuli. 
Table 1. SAM Mean Pleasure and Arousal Ratings of Pleasant, Neutral, and Unpleasant Adjectives Rated by 45 Students of the University of Konstanz

\begin{tabular}{lccc}
\hline \hline \multirow{2}{*}{$\begin{array}{c}\text { Mean pleasure and } \\
\text { arousal ratings }\end{array}$} & \multicolumn{3}{c}{ Words } \\
\cline { 2 - 4 } & Pleasant & Neutral & Unpleasant \\
\hline Pleasure & $6.6(0.097)$ & $4.7(0.079)$ & $2.9(0.066)$ \\
Arousal & $5.3(0.105)$ & $3.8(0.118)$ & $5.5(0.108)$ \\
\hline
\end{tabular}

The range and direction of the SAM ratings are as follows: pleasure $=9$ (extremely pleasant) to 1 (extremely unpleasant), arousal $=9$ (extremely arousing) to 1 (not at all arousing). Standard errors are given in parentheses.

One hundred eighty adjectives (60 highly arousing pleasant, 60 highly arousing unpleasant, and 60 neutral, low arousing adjectives) were selected from a pool of 500 adjectives according to the ratings of 45 student subjects. Ratings were obtained on the dimensions of perceived arousal and valence using a computerized version of the Self-Assessment Manikin (SAM; Lang \& Cuthbert, 1984). The pleasant and unpleasant adjectives were matched for perceived arousal. They did not differ significantly from each other but differed significantly from the neutral adjectives on this dimension, $F(2,177)=66.3, p<.001$.

Adjectives were further selected to be comparable in mean word length, $F(2,177)=0.24, p=.78$, and word frequency, $F(2,177)=2.0, p=.14$. Word frequency was controlled using frequency counts for written language from the standardized word-database CELEX (Baayen, Piepenbrock, \& Gulikers, 1995). Table 1 shows means and standard errors of the rating data in each emotional category.

Adjectives were presented for $5 \mathrm{~s}$ in black letters centered on a white computer screen with an interstimulus interval (ISI) of $1000 \mathrm{~ms}$. Presentation order was randomized across emotional categories and subjects. For each subject, a startle tone occurred at a random time point, $2500-4000 \mathrm{~ms}$ after word onset during 20 of the words from each valence category, resulting in a $33 \%$ probability of startle tone occurrence. The assignment of startle tones to the words was randomly determined and individually different for each subject. One startle tone per word category occurred at 0-300 ms and one at 4700-5000 ms after word onset to reduce the predictability of startle tone presentation. These six trials were excluded from further analyses.

The acoustic startle stimuli consisted of $90-\mathrm{dB}$ sound pressure level bursts of white noise with $50 \mathrm{~ms}$ duration and instantaneous rise and fall times. Startle probes were presented binaurally through stereo headphones. To avoid baseline shifts in muscle or central nervous system activity, word sequence was controlled such that startled words were never consecutive. In addition, no more than two words from a category occurred in sequence and presentation sequence of words from different word categories shared convergence in probability. Word sequence and startle tone presentation were balanced across valence categories and across subjects. Experimental runs were generated and controlled by "Presentation" software (Neurobehavioral Systems, Inc.).

\section{Procedure}

Subjects were familiarized with the laboratory setting, the experiment was explained to them in general terms, they were questioned with regard to their medical status, their handedness was determined, and they signed an informed consent form. Thereafter, electroencephalographic (EEG) and EMG electrodes were attached, and participants were familiarized with the experimental instructions. The instructions were designed to enhance active processing of the presented stimuli: Participants were told that emotional adjectives would be presented for $5 \mathrm{~s}$ each and that they should covertly evaluate their emotional meaning, that is, whether they regarded a word as emotionally unpleasant, pleasant, or neutral, and try to memorize them for a subsequent test. They were also told to ignore all of the randomly occurring loud tones, played through headphones. Subjects were instructed to keep their eyes open and fixate on the center of the screen for the entire time of word presentation.

\section{Physiological Data Collection and Reduction}

EMG and EEG data were recorded using a NEUROSCAN SynAmps amplifier and software.

Electromyographic recording. The eyeblink component of the startle reflex was recorded electromyographically from the orbicularis oculi muscle beneath the left and right eyes, using miniature $\mathrm{Ag} / \mathrm{AgCl}$ electrodes (5 $\mathrm{mm}$ in diameter). The electrodes were placed $1 \mathrm{~cm}$ apart beneath both eyes. Interelectrode distance was kept constant for both eyes and all subjects.

The continuously recorded EMG signal was collected with a bandpass from DC to $500 \mathrm{~Hz}$, amplified by 500 and sampled at $2000 \mathrm{~Hz}$. EMG electrode impedance was held beneath $5 \mathrm{k} \Omega$. Offline, the digital EMG signal was bandpass filtered at $28-500 \mathrm{~Hz}$ and rectified. Startle blinks were measured off-line from $100 \mathrm{~ms}$ before until $300 \mathrm{~ms}$ after the onset of each startle probe scoring onset latency in milliseconds and peaks in microvolts for each trial and word category. Startle segments were baseline corrected using the interval before onset of the visual stimulus from $100 \mathrm{~ms}$ before until word onset.

Exclusion criteria for baseline corrected peak and latency scoring were a response onset before $20 \mathrm{~ms}$ or a response peak later than $200 \mathrm{~ms}$ after probe onset, as well as an onset-to-peak latency greater than $120 \mathrm{~ms}$. Additionally, as subjects were not adapted to startle tones before the experiment, the first recorded blink of each word category and subject was rejected from further analysis. For each subject, EMG eyeblink amplitude averages were computed for the individual emotional word categories. Latency of startle peaks was measured, but no valence effects were detected and thus latency is not further reported here. Recording and analysis of startle data followed recommendations by Berg and Balaban, (1999) and Blumenthal et al. (2005).

Electroencephalographic recording. The EEG was recorded from 64 channels, using an EasyCap system. Raw EEG data were collected with a bandpass from DC to $500 \mathrm{~Hz}$, sampled at $2000 \mathrm{~Hz}$, and down-sampled off-line to $256 \mathrm{~Hz}$. All EEG channels were recorded against a Vertex reference $(\mathrm{Cz})$ and converted off-line to an average reference. For all electrodes, recording impedance was held beneath $5 \mathrm{k} \Omega$. Filtering, artifact rejection, and analyses of the ERP responses followed off-line: Data were filtered from 0.53 to $30 \mathrm{~Hz}$. ${ }^{1}$ Filtered data were corrected for eye movement artifacts using the ocular correction algorithm of Ille,

\footnotetext{
${ }^{1}$ Some studies investigating P3 and LPC components have used lower highpass filters than we did (e.g., $0.1 \mathrm{~Hz}$ or $0.03 \mathrm{~Hz}$ ). Although this may affect the general morphology of the late components, it will not annihilate experimental effects (see Duncan-Johnson and Donchin, 1979). Specifically, differences in late components observed with a higher highpass filter will not vanish with a lower filter setting, although the converse may be true. Thus, a higher filter setting, like the one we used, will result in a more conservative estimation of the experimental differences.
} 
Berg, and Scherg (2002). In addition a semiautomatic artifact rejection as implemented in BESA (MEGIS Software $\mathrm{GmbH}$ ) was run to eliminate remaining artifacts. Artifact-free EEG data were segmented from $100 \mathrm{~ms}$ before word onset until $4000 \mathrm{~ms}$ after word onset and baseline corrected using the $100 \mathrm{~ms}$ before word onset as a baseline for both the visually and the auditory evoked potentials.

Visually evoked potentials. For each subject, visually evoked ERP components for startled words were averaged for each word category separately: The N1, P2, P3, and LPC components were scored by determining the mean activity on averaged waveforms for each subject, valence category, and sensor. N1 was determined within a time window starting from $50 \mathrm{~ms}$ to $180 \mathrm{~ms}$ after word onset. P2 was determined using the time window from $180 \mathrm{~ms}$ until $250 \mathrm{~ms}$ after word onset and P3 amplitudes were analyzed from $250 \mathrm{~ms}$ until $400 \mathrm{~ms}$ after word onset. The visually evoked LPC complex was scored from $600 \mathrm{~ms}$ to $750 \mathrm{~ms}$ after word onset.

The N1 component was determined at a group of parietooccipital electrodes including PO3, PO4, P1, P2, Pz, O1, O2, O9, $\mathrm{O} 10$, and $\mathrm{Oz}$. The P2, P3, and LPC visual components were scored at a group comprising P1, P2, P5, P7, C5, C4, Pz, Cz, $\mathrm{CP} 5, \mathrm{CP} 4$, and $\mathrm{CPz}$. The averaged activities from these groups of electrodes were, for each component individually, entered into the statistical analysis to get a topographically stable estimate of the underlying brain activity without inflating the likelihood of type I errors.

Auditory evoked potentials. The acoustically elicited N1 and P3 components of the startle tones were determined for each word category and subject. The N1 was determined as the mean activity within a time window from $80 \mathrm{~ms}$ to $180 \mathrm{~ms}$ after startle tone presentation for each subject, valence category, and sensor. The startle P3 amplitude was analyzed within $280 \mathrm{~ms}$ to $380 \mathrm{~ms}$ after startle tone onset. P3 latency was also measured, but no effects of valence on latency were observed.

The startle tone $\mathrm{N} 1$ as well as the startle tone $\mathrm{P} 3$ waveforms were statistically tested at the following group of electrodes: $\mathrm{FCz}$, $\mathrm{Cz}, \mathrm{CPz}, \mathrm{Pz}, \mathrm{FC} 1, \mathrm{FC} 2, \mathrm{C} 3, \mathrm{C} 4, \mathrm{CP} 1, \mathrm{CP} 2, \mathrm{CP} 3, \mathrm{CP} 4, \mathrm{P} 1$, and $\mathrm{P} 2$. Statistical analysis for both the N1 and the P3 startle tone amplitudes is reported for the averaged activity from this group of electrodes.

\section{Statistical Data Analysis}

Startle eyeblink. To examine affective modulation of the startle reflex during word processing, blink amplitude was analyzed in a repeated measures analysis of variance (ANOVA), in- volving the factors Word Valence (pleasant, unpleasant, and neutral) and Eye (left, right) as within-subject factors. Post hoc planned comparisons were used to compare the three affective categories. Where appropriate, significance levels for EMG data are reported after adjustment for violations of the sphericity assumption using the Huynh-Feldt procedure.

ERPs. To test basic effects of emotional word processing on visually evoked potentials and auditory startle P3 modulation, a one-way repeated measures ANOVA was calculated containing the variable Valence (pleasant, unpleasant, and neutral word categories) as repeated measures. Based on representative ERP topographies Valence effects were statistically tested at averages of the electrode groups described above. For significant main effects post hoc analyses for ERP amplitudes were performed, using planned comparison tests.

Significance levels for ERP data are reported after adjustment for violations of the sphericity assumption using the HuynhFeldt procedure, where warranted.

\section{Results}

\section{Startle Eyeblink}

The peak amplitude of the EMG startle eyeblink component varied with word category (Word Valence, $F[2,50]=8.98$, $p<.005)$. The means and standard errors for EMG eyeblink responses elicited by the startle tone during processing of pleasant, unpleasant, and neutral adjectives as well as the significance levels of post hoc tests are given in Table 2. No significant effect for the main factor Eye was obtained, $F(1,25)=0.88, p>.36$. Affective blink facilitation for pleasant words was found for both eyes and did not differ between left or right recording sites (Valence $\times$ Eye, $F[2,50]=2.4, p>.09$ ).

\section{Auditory Startle Evoked Potentials}

Means and standard errors of the auditory cortical brain potentials elicited by the startle tone for the three different conditions are presented in Table 2, together with relevant post hoc comparisons. Grand average waveforms of the auditory cortical brain potentials elicited by the startle tone during processing of pleasant, unpleasant, and neutral adjectives are presented in Figure 1.

Auditory N1. The acoustically elicited startle tone N1 amplitude did not vary significantly with stimulus valence, indicating that the startle tones at this early stage were equally processed, regardless of whether the foregrounds were emotional or neutral in meaning.

Table 2. Means ( \pm Standard Errors) of the Electromyographic Startle Response (EMG) and the Auditory Event-Related Brain Potentials (N1 and P3) to the Startle Tone, Separately for Pleasant, Unpleasant, and Neutral Foregrounds

\begin{tabular}{|c|c|c|c|c|}
\hline \multirow[b]{2}{*}{ Variables (time window) } & \multicolumn{4}{|c|}{ Emotional content } \\
\hline & Pleasant & Neutral & Unpleasant & $F(2,50)(p)$ \\
\hline Startle EMG (peak) & $15.91(4.3)^{\mathrm{a}}$ & $14.82(4.3)^{\mathrm{b}}$ & $13.05(3.6)^{\mathrm{c}}$ & $8.98(<.005)$ \\
\hline Startle ERP N1 (80-180 ms) & $-4.54(1.64)^{\mathrm{a}}$ & $-4.55(1.43)^{\mathrm{a}}$ & $-4.26(1.50)^{\mathrm{a}}$ & .97 (n.s.) \\
\hline Startle ERP P3 (280-380 ms) & $4.31(0.44)^{\mathrm{b}}$ & $3.86(0.42)^{\mathrm{a}}$ & $3.78(0.43)^{\mathrm{a}}$ & $4.7(<.01)$ \\
\hline
\end{tabular}

Notes: Mean EMG values represent the mean activity of averaged waveforms across the left and the right eyes. Mean values for the acoustically elicited $\mathrm{N} 1$ and P3 startle tone potentials represent the mean activity of waveforms across 14 electrodes for the time windows indicated. Mean values are presented in microvolts. The table shows the average physiological responses elicited by the startle tone in the different foreground conditions and their statistical significance. The rightmost column shows the $F$ values for the main effects of the emotional content of adjectives with the corresponding $p$ values in parentheses. Different superscripts $(\mathrm{a}, \mathrm{b}, \mathrm{c})$ on numbers within each row indicate that the means are significantly different $(p<.05)$ using post hoc planned comparison tests. Same superscripts (a) on numbers within each row indicate that the means are not significantly different $(p<.05)$ from each other using planned comparison tests. 


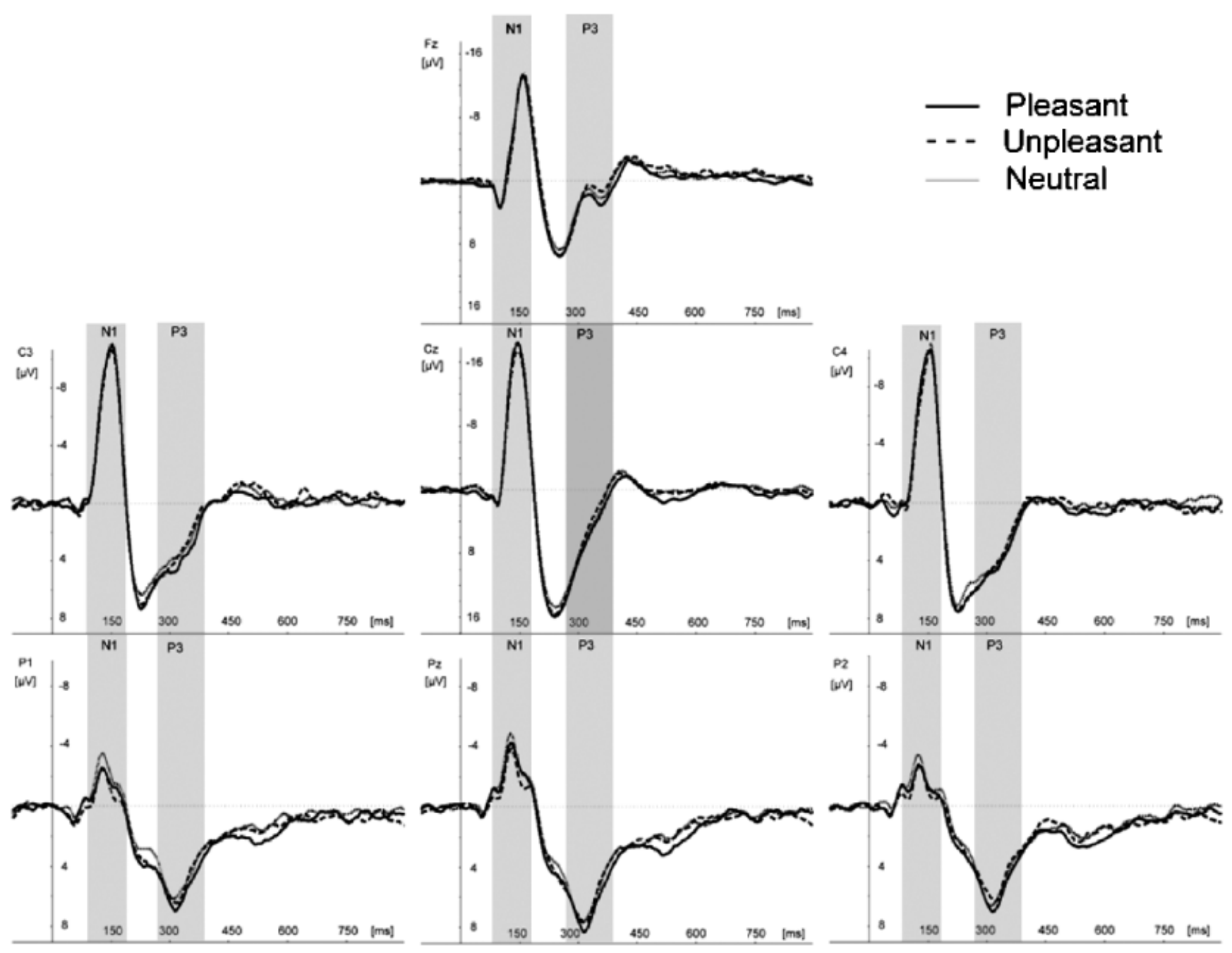

Figure 1. Effects of startle P3 modulation during viewing pleasant, unpleasant, and neutral adjectives.

Auditory P3. The valence of the foreground words affected the auditory P3 response. Startle P3 amplitude was more pronounced for pleasant words in comparison to unpleasant words.

\section{Visually Evoked Potentials}

Means and standard errors for all analyzed components of the visually evoked potential as well as relevant post hoc comparisons are detailed in Table 3, separately for each condition. The time courses of the ERPs recorded during processing pleasant, unpleasant, and neutral words are shown in Figure 2.

Visual N1. As in the analyses of the auditory evoked N1, the acoustically elicited startle tone N1 amplitude did not vary significantly with stimulus valence, indicating that all words, regardless of their emotional meaning, were initially responded to in a similar manner.

Table 3. Mean Voltages ( \pm Standard Errors) of the Visual Event-Related Potential Evoked by Pleasant, Unpleasant, and Neutral Adjectives

\begin{tabular}{lrrr}
\hline \hline & & \multicolumn{2}{c}{ Emotional content } \\
\cline { 2 - 4 } Variables (time window) & Pleasant & Neutral & Unpleasant \\
\hline N1 $(50-180 \mathrm{~ms})$ & $-0.47(0.20)^{\mathrm{a}}$ & $-0.68(0.20)^{\mathrm{a}}$ & $-0.35(0.21)^{\mathrm{a}}$ \\
P2 $(180-250 \mathrm{~ms})$ & $0.63(0.19)^{\mathrm{a}}$ & $0.17(0.19)^{\mathrm{b}}$ & $0.62(0.19)^{\mathrm{a}}$ \\
P3 $(250-400 \mathrm{~ms})$ & $0.97(0.14)^{\mathrm{a}}$ & $0.64(0.18)^{\mathrm{b}}$ & $0.99(0.16)^{\mathrm{a}}$ \\
LPC $(600-750 \mathrm{~ms})$ & $0.63(0.12)^{\mathrm{b}}$ & $0.17(0.15)^{\mathrm{a}}$ & $3.1(<.01)$ \\
\hline \hline
\end{tabular}

Notes: Values for the visually elicited N1 potential represent the mean activity obtained from 10 parieto-occipital electrodes during the time-window indicated. Values for the visually elicited P2, P3, and LPC potentials represent the mean activity obtained from 11 centro-parietal electrodes during the time-window indicated. Table shows ERP responses to adjectives of different emotional categories. The rightmost column shows the $F$ values from statistical analyses of the main effects of content during processing of pleasant, unpleasant, and neutral adjectives. The corresponding significant $p$ values are presented in parentheses. Different superscripts $(a, b, c)$ on numbers within each row indicate that the mean voltage activities on averaged waveforms are significantly different $(p<.05)$ using post hoc planned comparison tests. Same superscripts (a) on numbers within each row indicate that the means do not differ significantly. 

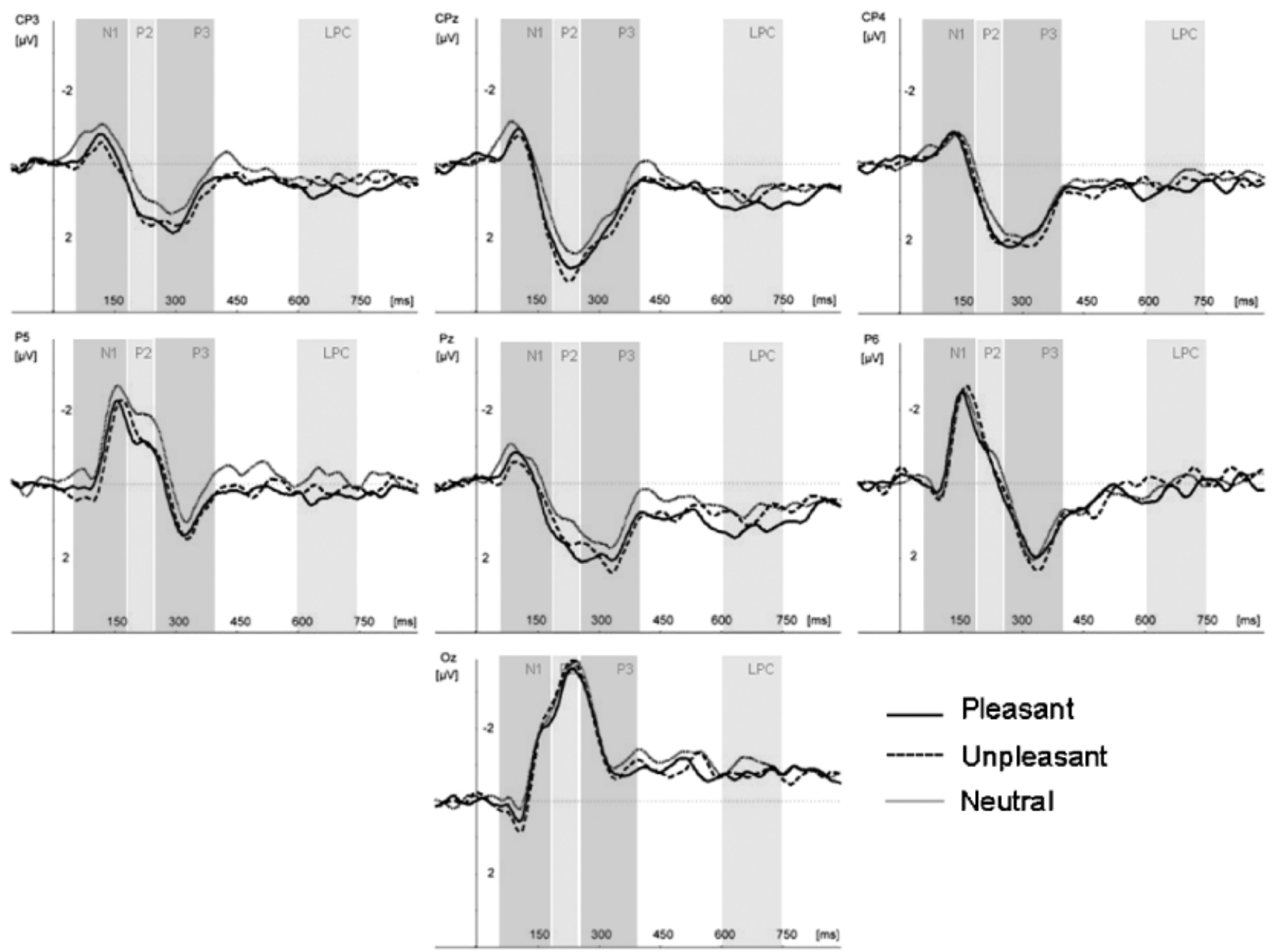

Figure 2. Visual event-related potentials during viewing pleasant, unpleasant, and neutral adjectives at central, centro-parietal, parietal, and occipital electrodes.

Visual P2. In contrast to nonsignificant results for the N1 amplitude, the visual P2 potential was significantly more pronounced for both unpleasant and pleasant relative to neutral adjectives.

Visual P3. Processing of positively and negatively valenced adjectives elicited significantly larger P3 potentials of the visually evoked brain potential than processing of neutral adjectives. Regardless of valence, emotional words drew more attention than neutral ones.

LPC component. Emotional valence of the presented words also affected the visual LPC potential. In contrast to larger P2 and P3 modulation for both unpleasant and pleasant adjectives, post hoc comparisons revealed that processing pleasant words produced significantly larger LPC potentials compared to unpleasant and neutral ones. Larger LPC activity for pleasant adjectives than for both neutral and unpleasant adjectives might signal that subjects were more engrossed in evaluative encoding of pleasant words.

\section{Correlation Analysis}

For pleasant foregrounds, we observed a parallel between increased LPC and the startle tone P3 brain potential as well as the
EMG startle eyeblink response. To explore whether this relationship could be statistically confirmed, correlations were calculated to quantify the strength of this association for each emotion category individually. For pleasant adjectives, significant correlations (Pearson's $r$ ) were observed between the LPC activity and the magnitude of the auditory startle $\mathrm{P} 3$ amplitude, $r=.57, p<.01$, as well as the LPC activity and the magnitude of the startle eyeblink response, $r=.47, p<.05$. No significant correlations were found for either the neutral or unpleasant stimuli, all $p s>$.1. Of note, there was no significant correlation between visual P3 amplitude and any measure of startle reactivity for any valence category, all $p>.1$.

These results support the view that sustained processing of pleasant words in our study is an important factor for the increased startle reactivity found when subjects were engaged in the processing of words with pleasant rather than unpleasant or neutral meaning. Figure 3 displays the significant correlations obtained between cortical positivity (LPC) and startle reactivity during viewing pleasant adjectives.

\section{Discussion}

We examined the extent to which affective startle reflex modulation occurs when people evaluate visually presented emotional 

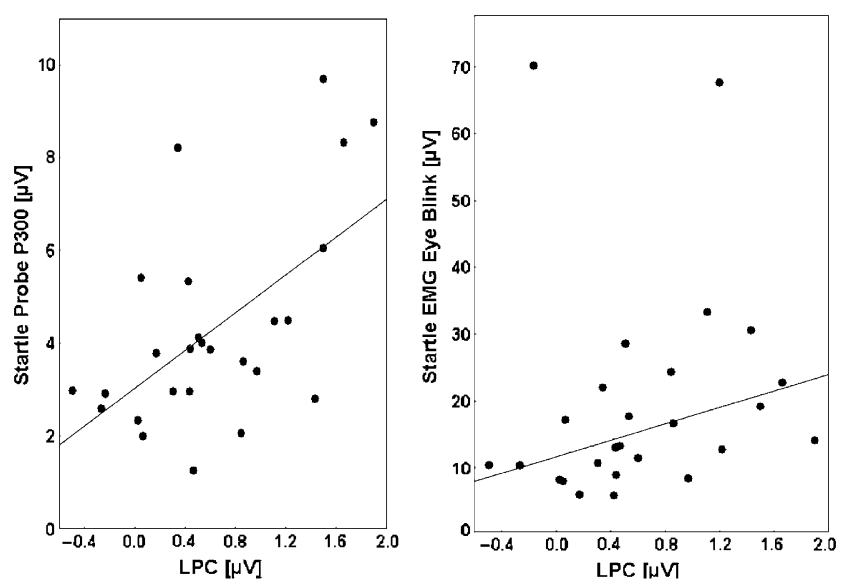

Figure 3. Regression plots obtained for cortical positivity (LPC analysis) and startle reactivity during processing of pleasant adjectives. The left panel shows LPC amplitude plotted against auditory startle P3 amplitude; the right panel shows LPC amplitude plotted against EMG startle amplitude. Two subjects produced remarkably large startle responses (see Figure 3, right panel). We excluded these outliers from the EMG correlation analysis and also recalculated all other analyses without these subjects. This affected neither the direction nor the significance levels of the results.

adjectives, measuring the EMG eyeblink component and the auditory evoked probe P3 of the startle tone. Additionally, we examined processing of the affective foregrounds through analysis of the visually evoked cortical potential and quantified the relationship between cortical processing of the foreground stimuli and cortical (probe P3) as well EMG indices of startle reactivity.

The verbal emotional foreground had a significant impact on both the peripheral and the central nervous physiological measures of the startle response. Both startle EMG amplitude and auditory evoked P3 amplitude were larger for pleasant than for neutral and unpleasant verbal foregrounds. Differential processing of the emotional adjectives could be ascertained through analysis of the visually evoked potentials elicited during word processing. In the P2 and P3 time windows, both pleasant and unpleasant adjectives were associated with larger positivities than neutral words, indicating the allocation of more resources to emotional adjectives, regardless of valence. Further elaboration (as reflected in the late positive component) was only present during processing of pleasant words and was correlated with EMG and auditory $\mathrm{P} 3$ responses to the startle tone.

A pronounced $\mathrm{P} 2$ component when reading emotional words has been described by Bernat et al. (2001) and related to conscious processing of affective content. Moreover, enhanced P2 responses to visually presented panic-related words were found in panic disorder patients (Pauli, Amrhein, Dengler, \& Wiedemann, 2005). An enlargement of the visually evoked P3 to emotional compared to neutral adjectives, regardless of processing task (structural vs. affective), was reported by Naumann and colleagues (1992). In the late positive component time window, evoked responses to pleasant adjectives continued to be amplified whereas brain responses to unpleasant and neutral words did not differ any longer. Larger late positive components during emotional word processing have been reported in a number of previous studies (Knost et al., 1997; Naumann et al., 1992; Williamson, Harpur, \& Hare, 1991) as an index of enhanced elaborative processing (Paller, Kutas, \& McIsaac, 1995). Thus, in the present study both pleasant and unpleasant adjectives received more attention than neutral words, but pleasant adjectives only were further elaborated.

Startle potentiation with unpleasant linguistic emotional foregrounds has been reported to occur at very short lead intervals (Aitken et al., 1999; Knost et al., 1997; Waters et al., 2000). However, both the present and previous data show that when the startle tone is presented at later SOAs different patterns are obtained: Here, as in the studies of Aitken et al. (1999) and Waters et al. (2000), no modulation of the startle eyeblink by unpleasant verbal foregrounds at lead intervals $\geq 2000 \mathrm{~ms}$ was found. Unfortunately, neither of the previous studies has assessed responses to pleasant foregrounds or used central nervous indices of lead and startle stimulus processing. Knost et al. (1997) also focused on unpleasant lead words at extremely short lead intervals (1.25 $\mathrm{ms}$ after word onset) but assessed visually evoked brain responses to the lead stimuli. The study found both enhanced startle EMG and larger LPC potentials to the emotional, albeit unpleasant, than to the neutral words. A parallel between the cortical processing stage and startle amplitude is also reported by Baas, Kenemans, Böcker, and Verbaten (2002), who reported larger startle responses and a pronounced protracted parietal positivity for simple grating stimuli that served as forewarning signals of an imminent shock. The parallel between EMG response patterns and the late positive component across studies suggests a relationship between the processing stage of the foreground stimulus and the size and direction of the startle response.

Previous text imagery research suggests that startle reactivity covaries with the depth of internal cognitive processing (Miller et al., 2002; Panayiotou \& Vrana, 1998; Sabatinelli et al., 2001). According to these authors, startle reactivity is influenced by the degree of internal processing or active disengagement from the sensory environment. It is assumed that when people are actively engaged in internal processing, a startle tone serves as an alerting stimulus, and the EMG startle response is facilitated regardless of stimulus valence (Miller et al., 2002). This study supports this thesis by finding significant correlations between LPC magnitude for pleasant adjectives and both EMG and ERP measures of startle.

Instructing our subjects to evaluate the emotional meaning of the presented words and to memorize them should direct subjects' cognitive resources away from perceptual processing of the presented words and increase mental load on internal processes. Under such circumstances, in accordance with Miller et al. (2002), we suggest that evaluative word viewing, like textprompted imagery, is a "cognitive-mentational task" that relies on elaborative internal processing and involves active disengagement from sensory input. The visually evoked potential tracings in response to the word stimuli clearly demonstrate that, at least during later stages of processing, subjects were more engrossed in processing of the pleasant than of the neutral or unpleasant materials. Thus, a larger processing interrupt effect will result for the pleasant adjectives leading to larger EMG blink responses.

When startle tones occurred during pleasant adjectives, the auditory startle $\mathrm{P} 3$ response to the tone was likewise enlarged in comparison to unpleasant and neutral words. At first glance, this may appear surprising in view of findings of reduced probe P3 coinciding with facilitated EMG startle (Cuthbert et al., 2000; Schupp et al., 1997), which have been accounted for in terms of resource competition. However, so far no study has directly investigated auditory startle probe P3 under conditions of interrupted internal mental engagement. In fact, it is reasonable to assume that when subjects are suddenly re-alerted from mental 
engagement to their physical environment this "call to arms" will be associated with enhanced processing of all aspects of the alerting stimulus, including heightened alertness to the stimulus and response preparation (Graham, 1979; Lacey, 1967). Graham first suggested that the startle response provides a protective function by interrupting internally focused processes and mobilizing the organism to respond to significant changes in the environment. As Miller et al. (2002) put it: "Without such an interrupt mechanism, non-perceptual processing would leave the organism highly vulnerable to environmental threat" (p. 527).

Electrophysiologically, our results demonstrate that this interruptive call to arms results in enhanced amplitudes of the auditory startle P3. Generally, P3 is assumed to be related to attention (Donchin \& Coles, 1988; Verleger, 1988), but it can also be elicited by salient stimuli such as loud noises when no task is assigned (Ford, Roth, \& Kopell, 1976). Ford and Roth (1999), on the basis of pilot data, assumed that like blink facilitation, startle P3 amplitude should be enhanced as a consequence of successful re-alerting to salient startling tones, especially after long lead intervals. Our results corroborate the interpretation of increased startle eyeblink responses and startle P3 as a consequence of successful processing interrupt, both via the LPC indices of mental engagement and the correlation of LPC magnitude with both EMG startle eyeblink and auditory startle P3 amplitude during processing of pleasant adjectives.

The question remains as to why particularly the pleasant adjectives were subject to more processing than the other two emotional categories: We used pleasant and unpleasant words that were highly arousing according to normative ratings and preferentially drew subjects' initial attention as evidenced by the visual ERP effects at P2 and P3 for both pleasant and unpleasant adjectives. However, the unpleasant stimuli did not show a heightened late positive component and did not affect the startle reflex. This may be due to asymmetries in emotional processing: At low levels of arousal a "positivity offset" is often found in that the approach system responds more strongly to relatively little input. The withdrawal system in response to unpleasant input, in turn, is activated comparatively more at high levels of arousal, this latter process being termed "negativity bias" (Cacioppo, 2004; Ito \& Cacioppo, 2000). In picture viewing studies with long lead intervals, the classic finding of startle potentiation for unpleasant and startle inhibition for pleasant material is only observed at the highest arousal levels, whereas at medium or low levels of arousal, the pattern is more variable or can even be reversed (Cuthbert et al., 1996). It is reasonable to assume that visually presented words generally constitute less arousing stimuli than complex colored pictures, that is, the word cruel will be less arousing than a photograph of a corresponding scene, even if both stimuli receive comparable ratings. ${ }^{2}$ Therefore, in the absence of strong personal associations for a word (which may have been present in various clinical populations that have previously been studied) a positivity offset for written verbal material can be expected.

Recent neuroscientific studies support this reasoning: Hamann and Mao (2001) report that when subjects explicitly evaluate verbal stimuli, unpleasant as well as pleasant nouns elicit activity in the left amygdala, but only pleasant nouns additionally activate dorsal and ventral striatal regions related to reward and positive affect, involving caudate, putamen, globus pallidus, and nucleus accumbens. All the foregoing brain regions have been found to modulate the startle circuitry (see Skolnick \& Davidson, 2002). Fossati and colleagues (2003) measured cerebral blood flow while experimental subjects evaluated emotional adjectives in relation to themselves and found stronger brain activation for pleasant than for unpleasant words in the insula, superior temporal, and parietal brain regions.

A bias in favor of pleasant words is also found in categorization paradigms: Reaction time advantages for pleasant words have repeatedly been reported for the emotional categorization of words (Feyereisen, Malet, \& Martin, 1986; Kiehl, Hare, McDonald, \& Brink, 1999; Lehr, Bergum, \& Standing, 1966; Osgood \& Hoosain, 1983; Stenberg, Wiking, \& Dahl, 1998) and faces (Feyereisen et al., 1986; Hugdahl, Iversen, \& Johnson, 1993; Leppänen \& Hietanen, 2003, 2004). These results underscore an important role of the task and processing stage in the emergence of pleasant-unpleasant asymmetries. Whereas early stimulus registration may be largely arousal driven or even prioritize highly arousing unpleasant stimuli (e.g., Dijksterhuis \& Aarts, 2003; Morris, Öhman, \& Dolan, 1999; hman, Lundquist, Esteves, 2001), pleasant words enjoy an advantage in evaluation and categorical decision (Leppänen \& Hietanen, 2004, 2005).

In the present study ERP indices of foreground and startle tone processing as well as EMG startle responses were examined with both pleasant and unpleasant adjectives as affective foregrounds. Prolonged cortical processing, as evidenced by the late positive component, enhanced auditory probe $\mathrm{P} 3$ responses, and startle potentiation were found for pleasant in comparison to neutral and unpleasant adjectives. Larger late positive components for pleasant adjectives statistically predicted more pronounced startle reactivity both in the EEG and in the EMG. We assume this relationship will hold in tasks that require elaborative internal processing. In these contexts, the startle tone will re-alert the subject to the environment, thereby amplifying various aspects of startle stimulus evaluation. We attribute the particular findings of enhanced elaboration of the pleasant stimuli to a positivity offset that occurs at lower levels of arousal and in stimulus categorization tasks.

\section{REFERENCES}

Aitken, C. J., Siddle, A. T., \& Lipp, O. V. (1999). The effect of threat and nonthreat word lead stimuli on blink modification. Psychophysiology, 36, 699-705.

Anthony, B. J., \& Graham, F. K. (1985). Blink reflex modification by selective attention: Evidence for the modulation of "automatic" processing. Biological Psychology, 21, 43-59.

Baas, J. M., Kenemans, J. L., Böcker, K. B., \& Verbaten, M. N. (2002). Threat-induced cortical processing and startle potentiation. NeuroReport, 13, 133-137.
Baayen, R. H., Piepenbrock, R., \& Gulikers, L. (1995). The CELEX Lexical Database (CD-ROM). Philadelphia, PA: Linguistic Data Consortium, University of Pennsylvania.

${ }^{2}$ The SAM rating scales hold only within a given set of stimulus materials and do not represent absolute values of a given attribute. Hence, a rating alue of nine on an arousal scale for pictures cannot be equated with the same value for other materials such as words. 
Berg, W. K., \& Balaban, M. T. (1999). Startle elicitation: Stimulus parameters, recording techniques, and quantification. In M. E. Dawson, A. M. Schell, \& A. H. Böhmelt (Eds.), Startle modification: Implications for neuroscience, cognitive science, and clinical science (pp. 157183). New York: Cambridge University Press.

Bernat, E., Bunce, S., \& Shevrin, H. (2001). Event-related brain potentials differentiate positive and negative mood adjectives during both supraliminal and subliminal visual processing. International Journal of Psychophysiology, 42, 11-34.

Blumenthal, T. D., Cuthbert, B. N., Filion, D. L., Hackley, S., Lipp, O. V., \& van Boxtel, A. (2005). Committee report: Guidelines for human startle eyeblink electromyographic studies. Psychophysiology, 42, $1-15$.

Bower, G. H. (1981). Mood and memory. American Pychologist, 36, 129-148.

Bradley, B. P., Mogg, K., \& Williams, R. (1994). Implicit and explicit memory for emotional information in non-clinical subjects. Behaviour Research and Therapy, 32, 65-78.

Cacioppo, J. T. (2004). Asymmetries in affect laden information processing. In J. T. Jost, M. R. Banaji, \& D. A. Prentice (Eds.), Perspectivism in social psychology: The yin and yang of scientific progress (pp. 8595). Washington, DC: American Psychological Association.

Cacioppo, J. T., Crites, S. L. Jr, \& Gardner, W. L. (1996). Attitudes to the right: Evaluative processing is associated with lateralized late positive event-related brain potentials. Personality and Social Psychology Bulletin, 22, 1205-1219.

Chapman, R. M., McCrary, J. W., Chapman, J. A., \& Martin, J. K. (1980). Behavioral and neural analysis of connotative meaning: Word classes and rating scales. Brain and Language, 11, 319-339.

Cuthbert, B. N., Bradley, M. M., \& Lang, P. J. (1996). Probing picture perception: Activation and emotion. Psychophysiology, 33, 103-111.

Cuthbert, B. N., Schupp, H. T., Bradley, M., Birbaumer, N., \& Lang, P. J. (2000). Brain potentials in affective picture processing: Covariation with autonomic arousal and affective report. Biological Psychology, $52,95-111$.

Cuthbert, B. N., Schupp, H. T., Bradley, M., McManis, M., \& Lang, P. J. (1998). Probing affective pictures: Attended startle and tone probes. Psychophysiology, 35, 344-347.

Dijksterhuis, A., \& Aarts, H. (2003). On wildebeests and humans: The preferential detection of negative stimuli. Psychological Science, 14, $14-18$.

Donchin, E., \& Coles, M. G. H. (1988). Is the P300 component a manifestation of context updating? Behavioral and Brain Sciences, 11, $357-374$.

Duncan-Johnson, C. C., \& Donchin, E. (1979). The time constant in P300 recording. Psychophysiology, 16, 53-55.

Feyereisen, P., Malet, C., \& Martin, Y. (1986). Is the faster processing of expressions of happiness modality-specific? In H. D. Ellis, M. A. Jeeves, F. Newcombe, \& A. Young (Eds.), Aspects of face processing (pp. 349-355). Boston: Martinus Nijhoff.

Ford, J. M., \& Pfefferbaum, A. (1991). Event-related potentials and eyeblink responses in automatic and controlled processing: Effects of age. Journal of Electroencephalography and Clinical Neurophysiology, 78, 361-377.

Ford, J. M., \& Roth, W. T. (1999). Event-related potential components and startle. In M. E. Dawson, A. M. Schell, \& A. H. Böhmelt (Eds.), Startle modification: Implications for neuroscience, cognitive science, and clinical science (pp. 284-299). New York: Cambridge University Press.

Ford, J. M., Roth, W. T., \& Kopell, B. S. (1976). Attention effects on auditory evoked potentials to infrequent events. Biological Psychology, 4, 65-77.

Fossati, P., Hevenor, S. J., Graham, S. J., Grady, C., Keightley, M. L., Craik, F., et al. (2003). In search of the emotional self: An fMRI study using positive and negative emotional words. American Journal of Psychiatry, 160, 1938-1945.

Graham, F. K. (1979). Distinguishing among orienting, defense, and startle reflexes. In H. D. Kimmel, E. H. van Olst, \& J. F. Orlebeke (Eds.), The orienting reflex in humans (pp. 137-167). Hillsdale, NJ: Erlbaum.

Hamann, S., \& Mao, H. (2001). Positive and negative emotional verbal stimuli elicit activity in the left amygdala. NeuroReport, 13, 15-19.

Hugdahl, K., Iversen, P. M., \& Johnsen, B. H. (1993). Laterality for facial expressions: Does the sex of subjects interact with the sex of the stimulus face? Cortex, 29, 325-331.
Ille, N., Berg, P., \& Scherg, M. (2002). Artifact correction of the ongoing EEG using spatial filters based on artifact and brain signal topographies. Journal of Clinical Neurophysiology, 19, 113-124.

Ito, T. A., \& Cacioppo, J. T. (2000). Electrophysiological evidence of implicit and explicit categorization processes. Journal of Experimental Social Psychology, 36, 660-676.

Keil, A., Bradley, M., Hauk, O., Rockstroh, B., Elbert, T., \& Lang, P. J. (2002). Large-scale neural correlates of affective picture processing. Psychophysiology, 39, 641-649.

Kiehl, K. A., Hare, R. D., McDonald, J. J., \& Brink, J. (1999). Semantic and affective processing in psychopaths: An event-related potential (ERP) study. Psychophysiology, 36, 765-774.

Knost, B., Flor, H., Braun, C., \& Birbaumer, N. (1997). Cerebral processing of words and the development of chronic pain. Psychophysiology, 34, 474-481.

Lacey, J. I. (1967). Somatic response patterning and stress: Some revisions of activation theory. In M. H. Appley \& R. Trumbull (Eds.). Psychological stress: Issues in research. New York: Appleton.

Lang, P. J. (1979). Presidential address, 1978. A bio-informational theory of emotional imagery. Psychophysiology, 16, 495-512.

Lang, P. J. (1995). The emotion probe. American Pychologist, 50, 372 385.

Lang, P. J., Bradley, M. M., \& Cuthbert, B. N. (1990). Emotion, attention, and the startle reflex. Psychophysiological Review, 97, 377-395.

Lang, P. J., \& Cuthbert, B. N. (1984). Affective information processing and the assessment of anxiety. Journal of Behavioral Assessment, 6, 369-395.

Lang, P. J., Greenwald, M. K., Bradley, M. M., \& Hamm, A. O. (1993). Looking at pictures: Affective, facial, visceral, and behavioral reactions. Psychophysiology, 30, 261-273.

Larsen, J. T., Norris, C. J., \& Cacioppo, J. T. (2003). Effects of positive and negative affect on electromyographic activity over the zygomaticus major and corrugator supercilii. Psychophysiology, 40, 776-785.

Lehr, D. J., Bergum, B. O., \& Standing, T. E. (1966). Response latency as a function of stimulus affect and presentation order. Perceptual and Motor Skills, 23, 1111-1116.

Leppänen, J. M., \& Hietanen, J. K. (2004). Positive facial expressions are recognized faster than negative facial expressions, but why? Psychological Research, 69, 22-29.

Leppänen, J. M., \& Hietanen, J. K. (2003). Affect and face perception: Odors modulate the recognition advantage of happy faces. Emotion, 3, 315-326.

Lipp, O. V., Blumenthal, T. D., \& Adam, A. R. (2001). Attentional modulation of blink startle at long, short, and very short lead intervals. Biological Psychology, 58, 89-103.

Miller, M. W., Patrick, C. J., \& Levenston, G. K. (2002). Affective imagery and the startle response: Probing mechanisms of modulation during pleasant scenes, personal experiences, and discrete negative emotions. Psychophysiology, 39, 519-529.

Morris, J. S., Öhman, A., \& Dolan, R. J. (1999). A subcortical pathway to the right amygdala mediating "unseen" fear. Proceedings of the National Academy of Sciences, USA, 96, 1680-1685.

Naumann, E., Bartussek, D., Diedrich, O., \& Laufer, M. E. (1992). Assessing cognitive and affective information processing functions of the brain by means of the late positive complex of the event-related potential. Journal of Psychophysiology, 6, 285-298.

Öhman, A., Lundqvist, D., \& Esteves, F. (2001). The face in the crowd revisited: A threat advantage with schematic stimuli. Journal of Personality and Social Psychology, 80, 381-396.

Oldfield, R. C. (1971). The assessment and analysis of handedness: The Edinburgh inventory. Neuropsychologia, 9, 97-113.

Osgood, C. E., \& Hoosain, R. (1983). Pollyanna II: Two types of negativity. The Journal of Psychology, 113, 151-160.

Paller, K. A., Kutas, M., \& McIsaac, H. K. (1995). Monitoring conscious recollection via the electrical activity of the brain. Psychological Science, 6, 107-111.

Panayiotou, G., \& Vrana, S. R. (1998). Effect of self-focused attention on the startle reflex, heart rate, and memory performance among socially anxious and nonanxious individuals. Psychophysiology, 35, 328-336.

Pauli, P., Amrhein, C., Dengler, W., \& Wiedemann, G. (2005). Electrocortical evidence for an early abnormal processing of panic-related words in panic disorder patients. International Journal of Psychophysiology, 57, 33-41. 
Postma, P., Kumari, V., Sharma, T., Hines, M., \& Gray, J. A. (2001). Startle response during smoking and $24 \mathrm{~h}$ after withdrawal predicts successful smoking cessation. Psychopharmacology, 156, 360-367.

Putnam, L. E., \& Roth, W. T. (1990). Effects of stimulus repetition, duration, and rise time on startle blink and automatically elicited P300. Psychophysiology, 27, 275-297.

Robinson, J. D., \& Vrana, S. R. (2000). The time course of emotional and attentional modulation of the startle eyeblink reflex during imagery. International Journal of Psychophysiology, 37, 275-289.

Sabatinelli, D., Bradley, M. M., \& Lang, P. J. (2001). Affective startle modulation in anticipation and perception. Psychophysiology, 38, 719-722.

Schupp, H. T., Cuthbert, B. N., Bradley, M. M., Birbaumer, N., \& Lang, P. J. (1997). Probe P3 and blinks: Two measures of affective startle modulation. Psychophysiology, 34, 1-6.

Silvert, L., Delplanque, S., Bouwalerh, H., Verpoort, C., \& Sequeira, H. (2004). Autonomic responding to aversive words without conscious valence discrimination. International Journal of Psychophysiology, 53, $135-145$.
Skolnick, A. S., \& Davidson, R. J. (2002). Affective modulation of eyeblink startle with reward and threat. Psychophysiology, 39, 835-851.

Stenberg, G., Wiking, S., \& Dahl, M. (1998). Judging words at face value: Interference in word processing reveals automatic processing of affective facial expressions. Cognition and Emotion, 12, 755-782.

Verleger, R. (1988). The true P3 is hard to see: Some comments on Kok's (1986) paper on degraded stimuli. Biological Psychology, 27, 45-50.

Vrana, S. R., Spence, E. L., \& Lang, P. J. (1988). The startle probe response: A new measure of emotion? Journal of Abnormal Psychology, 97, 487-491.

Waters, A. M., Lipp, O. V., \& Cobham, V. E. (2000). Investigation of threat-related attentional bias in anxious children using the startle eyeblink modification paradigm. Journal of Psychophysiology, 14, 142-150.

Williamson, S., Harpur, T. J., \& Hare, R. D. (1991). Abnormal processing of affective words by psychopaths. Psychophysiology, 28, 260-273.

(Received April 26, 2005; ACCEPTED January 6, 2006) 